\title{
COVID-19 infection: epidemiological, clinical, and radiological expression among adult population
}

\author{
Eman Ragab ${ }^{1 *}$ D, Asrar Helal Mahrous ${ }^{2}$ and Ghadeer Maher El Sheikh ${ }^{3}$
}

\begin{abstract}
Background: High-resolution computed tomography (HRCT) has proved to be an important diagnostic tool throughout the COVID-19 pandemic outbreaks. Increasing number of the infected personnel and shortage of real-time transcriptase polymerase chain reaction (RT-PCR) as well as its lower sensitivity made the $C T$ a backbone in diagnosis, assessment of severity, and follow-up of the cases.

Results: Two hundred forty patients were evaluated retrospectively for clinical, laboratory, and radiological expression in COVID-19 infection. One hundred eighty-six non-severe cases with home isolation and outpatient treatment and 54 severe cases needed hospitalization and oxygen support. Significant difference between both groups was encountered regarding the age, male gender, $>38^{\circ}$ fever, dyspnea, chest pain, hypertension, $\leq 93$ oxygen saturation, intensive care unit (ICU) admission, elevated D-dimer, high serum ferritin and troponin levels, and high CT-severity score (CT-SS) of the severe group. CT-SS showed a negative correlation with $\mathrm{O}_{2}$ saturation and patients' outcome $(r-0.73 / p 0.001$ and $r-0.56 / p 0.001$, respectively). Bilateral peripherally distributed ground glass opacities (GGOs) were the commonest imaging feature similar to the literature.
\end{abstract}

Conclusion: Older age, male gender, smoking, hypertension, low $\mathrm{O}_{2}$ saturation, increased $\mathrm{C} T$ score, high serum ferritin, and high D-dimer level are the most significant risk factors for severe COVID-19 pneumonia. Follow-up of the recovered severe cases is recommended to depict possible post COVID-19 lung fibrosis.

Keywords: COVID-19, Computed tomography, Pneumonia, Coronavirus infection

\section{Background}

Coronavirus family is enveloped positive-stranded RNA viruses accustomed to cause usual non-severe upper respiratory tract symptoms, similar to common cold infection. Unfortunately, new versions that have emerged from animal reservoirs over the last two decades led to serious and widespread morbidities and mortalities [1].

By the end of 2019, a novel coronavirus was recognized to result in an illness outbreak that emerged in China. The virus is currently known as the severe acute respiratory syndrome coronavirus 2 (SARS-CoV-2). The resultant disease is called

\footnotetext{
* Correspondence: emanragab2000@yahoo.com

'Department of Radiodiagnosis, Faculty of Medicine, Menoufia University,

Shibin el Kom, Menoufia 32511, Egypt

Full list of author information is available at the end of the article
}

coronavirus disease 2019 (COVID-19). In March 2020, the World Health Organization (WHO) declared the COVID-19 outbreak as a pandemic [2, 3].

The host receptor for SARS-CoV-2 cell entry is the same as for SARS-CoV, the angiotensin-converting enzyme 2 (ACE2) [4]. Signs and symptoms of coronavirus disease 2019 (COVID-19) may manifest 2 to 14 days following exposure. Common presentation can include fever, cough, and tiredness. Early symptoms of COVID19 may be just loss of taste or smell. Other symptoms like shortness of breath or difficulty breathing, muscle ache, chills, sore throat runny nose, headache, or chest pain have been reported [5].

Many articles have been published as a descriptive demonstration for imaging findings in cases with

\section{Springer Open}

(อ) The Author(s). 2020 Open Access This article is licensed under a Creative Commons Attribution 4.0 International License, which permits use, sharing, adaptation, distribution and reproduction in any medium or format, as long as you give appropriate credit to the original author(s) and the source, provide a link to the Creative Commons licence, and indicate if changes were made. The images or other third party material in this article are included in the article's Creative Commons licence, unless indicated otherwise in a credit line to the material. If material is not included in the article's Creative Commons licence and your intended use is not permitted by statutory regulation or exceeds the permitted use, you will need to obtain permission directly from the copyright holder. To view a copy of this licence, visit http://creativecommons.org/licenses/by/4.0/. 
COVID-19 infection with emphasis on computed tomography $(\mathrm{CT})$ in screening, diagnosis, and follow-up of COVID-19 pneumonia [6-9]. High-resolution computed tomography (HRCT) is considered a backbone tool in management of the disease [10]. The purpose of the current study was to correlate the clinical expression of the disease and the HRCT findings among adults.

\section{Methods}

\section{Cases}

This retrospective study included 240 participants from 25 March 2020 till 5 July 2020. One hundred forty were males $(58.3 \%)$ and 100 were females $(41.7 \%)$. Age range was $18-85$ years with mean $\pm \mathrm{SD}=45.82 \pm 16.74$. Clinical, laboratory, and radiological evaluation occurred within the first 5 days of the onset of the symptoms. The Institutional Research Ethics committee has approved the study, and a written informed consent was obtained from each patient.

\section{Epidemiological and clinical points of view}

The patients were included according to the following: (1) epidemiological background, traveling to areas with case reports or exposure to a confirmed case within 14 days prior to the onset of symptoms; (2) clinical and laboratory manifestations, the patients underwent complete history taking, general and local examination, laboratory tests including complete blood count (CBC), C-reactive protein (CRP), serum ferritin, D-dimer, and liver and kidney function tests; (3) imaging criteria for COVID-19 pneumonia; (4) real-time transcriptase polymerase chain reaction (RTPCR) of the nasopharyngeal swab for 188 cases.

\section{Image acquisition and analysis}

HRCT of the chest was done using a 160 slice MultiDetector Toshiba CT Aquilion Prime scanner. Patients were in supine position with head first. Image acquisition parameters were $100 \mathrm{kV}, 250 \mathrm{mAs}$, FOV $=400 \times$ $460 \mathrm{~mm}$, slice thickness $1.0 \mathrm{~mm}$, and inter-slice gap 1.0 $\mathrm{mm}$. The images were reviewed on VITREA workstation for interpretation.

Each chest scan was assessed for laterality involvement (unilateral/bilateral), number of lung lobes affected (unilobar/bilobar/multilobar), distribution/location of the lesions (peripheral $=$ outer third/central $=$ inner two thirds), lesion patterns (ground glass opacities/consolidations/ crazy paving/septal lines), special signs (air bronchogram/ vascular prominence/white lung/reverse halo), and other imaging findings (pleural effusion/mediastinal lymphadenopathy) (Figs. 1 and 2).

Determination of the CT severity score (CT-SS) is as follows: by anatomy, both lungs consist of five lobes.

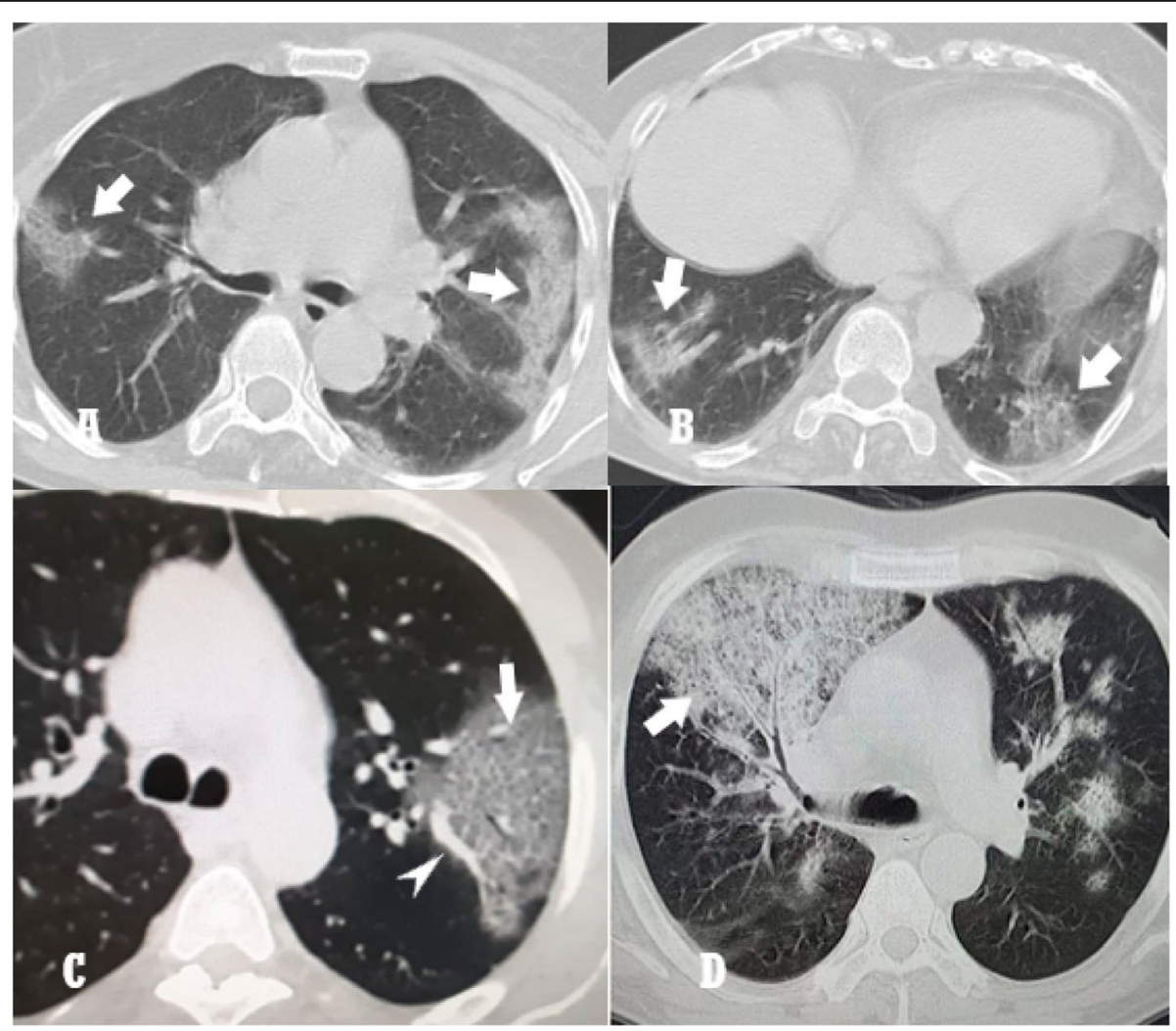

Fig. $\mathbf{1}$ a and $\mathbf{b}$ Ground glass opacities. c and $\mathbf{d}$ Crazy paving pattern. Note the vascular prominence (arrow head in c) 


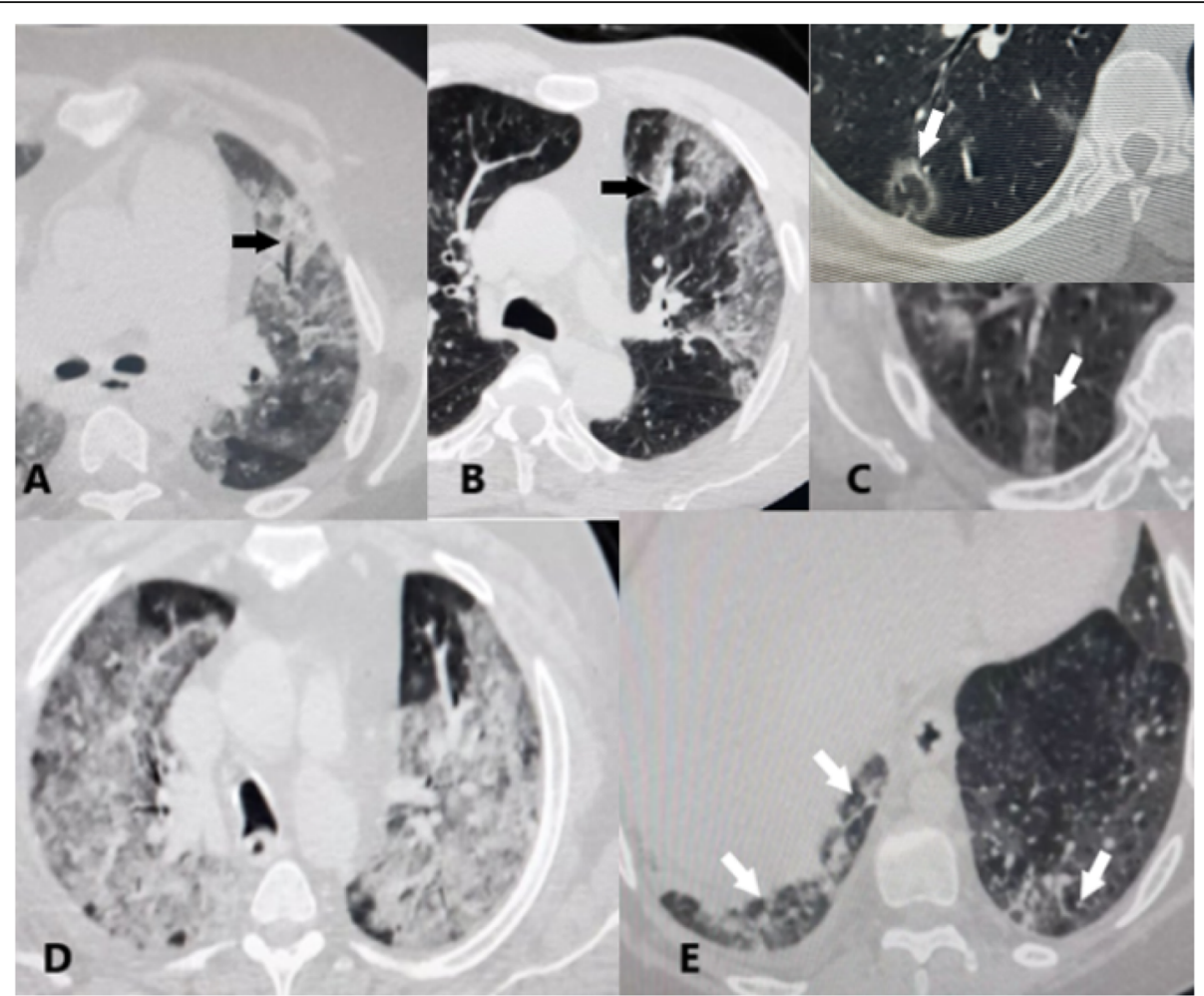

Fig. 2 a Air bronchogram sign. b Vascular prominence. c Reverse halo sign. d White lung sign. e Septal lines

Each lobe was assessed for affection, score $0=0 \%$ involvement; score 1 if < $5 \%$ involvement; score 2 if $5 \%$ to $<25 \%$ involvement; score 3 if 25 to $<50 \%$ involvement; score 4 if 50 to $<75 \%$ involvement; and score 5 if $\geq 75 \%$ involvement. Then, calculation of the total score that ranged from 0 to $25[11,12]$.

\section{Follow-up CT}

Eighteen cases underwent follow-up after discharge (about 5 weeks from the onset of the illness) due to recurrent dyspnea, and their $\mathrm{CT}$ showed strands of fibrosis as in Fig. 3.

\section{Statistical analysis}

The descriptive statistics are mean, standard deviation, and median for continuous data. The statistics for categorical variables are counts and percentages. Student's $t$ test and Mann-Whitney $U$ test were performed for continuous variables, and the $x^{2}$ test and Fisher exact test were used for categorical variables. $Z$ test was used to

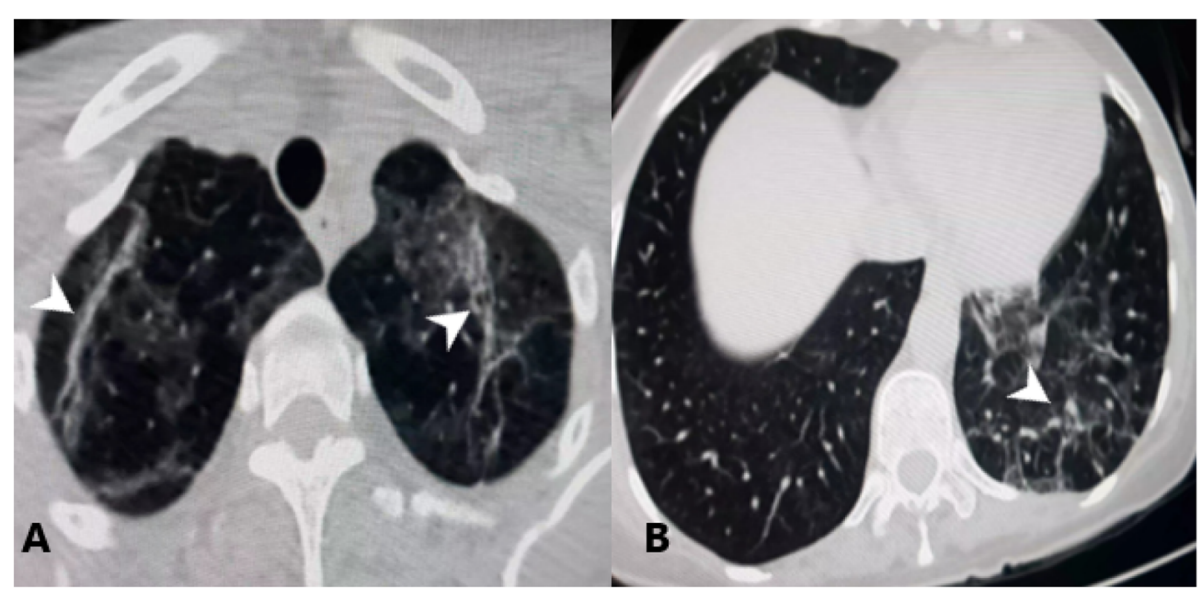

Fig. 3 Strands of fibrosis (arrow heads) 
Table 1 Demographic and clinical characteristics of the patients

\begin{tabular}{|c|c|c|c|c|}
\hline & All patients $(n=240)$ & Non-severe cases $(n=186)$ & Severe cases $(n=54)$ & $P$ value \\
\hline Age (years) & & & & .000 \\
\hline Mean \pm SD (median) & $45.82 \pm 16.74(44.0)$ & $41.88 \pm 14.55(42.00)$ & $59.37 \pm 16.67(62.00)$ & \\
\hline Range & $18-85$ & $18-75$ & $20-85$ & \\
\hline Age groups & & & & .000 \\
\hline$\geq 65$ years & $36(15.0 \%)$ & $10(5.4 \%)$ & $26(48.1 \%)$ & \\
\hline$<65$ years & $204(85.0 \%)$ & $176(94.6)$ & $28(51.9 \%)$ & \\
\hline Gender & & & & .000 \\
\hline Male & $140(58.3 \%)$ & $96(51.6 \%)$ & $44(81.5 \%)$ & \\
\hline Females & $100(41.7 \%)$ & $90(48.4 \%)$ & $10(18.5 \%)$ & \\
\hline Smoking history & & & & .006 \\
\hline Smoker & $116(48.3 \%)$ & $81(43.5 \%)$ & $35(64.8 \%)$ & \\
\hline Non-smoker & $124(51.7 \%)$ & $105(56.5 \%)$ & $19(35.2 \%)$ & \\
\hline Source of infection & & & & 0.67 \\
\hline Known source & $148(61.7 \%)$ & $116(62.4 \%)$ & $32(59.3 \%)$ & \\
\hline Unknown source & $92(38.3 \%)$ & $70(37.6 \%)$ & $22(40.7 \%)$ & \\
\hline Body temperature & & & & .001 \\
\hline$\leq 38^{\circ} \mathrm{C}$ & $142(59.2 \%)$ & $122(65.6 \%)$ & $20(37.0 \%)$ & \\
\hline$>38-39^{\circ} \mathrm{C}$ & $94(39.2 \%)$ & $62(33.3 \%)$ & $32(59.3 \%)$ & \\
\hline$>39^{\circ} \mathrm{C}$ & $4(1.7 \%)$ & $2(1.1 \%)$ & $2(3.7 \%)$ & \\
\hline Malaise & $150(62.5 \%)$ & $120(64.5 \%)$ & $30(55.6 \%)$ & 0.23 \\
\hline Bone ache/myalgia & $142(59.2 \%)$ & $104(55.9 \%)$ & $38(70.4 \%)$ & 0.06 \\
\hline Loss of taste/smell & $94(39.2 \%)$ & $92(49.5 \%)$ & $2(3.7 \%)$ & .000 \\
\hline Headache & $76(31.7 \%)$ & $68(36.6 \%)$ & $8(14.8 \%)$ & 0.002 \\
\hline Sore throat & $102(42.5 \%)$ & $96(51.6 \%)$ & $6(11.1 \%)$ & .000 \\
\hline Runny nose & $86(35.8 \%)$ & $86(46.2 \%)$ & $0(0.0 \%)$ & .000 \\
\hline Dry cough & $202(84.2 \%)$ & $164(88.2 \%)$ & $38(70.4 \%)$ & 0.002 \\
\hline Dyspnea & $106(44.2 \%)$ & $58(31.2 \%)$ & $48(88.9 \%)$ & .000 \\
\hline Chest tightness & $176(73.3 \%)$ & $130(69.9 \%)$ & $46(85.2 \%)$ & 0.02 \\
\hline Chest pain & $4(1.7 \%)$ & $0(0.0 \%)$ & $4(7.4 \%)$ & .000 \\
\hline Expectoration & $38(15.8 \%)$ & $16(8.6 \%)$ & $22(40.7 \%)$ & .000 \\
\hline Abdominal pain & $86(35.8 \%)$ & $74(39.8 \%)$ & $12(22.2 \%)$ & .01 \\
\hline Diarrhea & $\begin{array}{l}70(29.2 \%) \\
170(70.8 \%)\end{array}$ & $\begin{array}{l}62(33.3 \%) \\
124(66.7 \%)\end{array}$ & $\begin{array}{l}8(14.8 \%) \\
46(85.2 \%)\end{array}$ & .008 \\
\hline Cardiovascular diseases & $6(2.5 \%)$ & $4(2.2 \%)$ & $2(3.7 \%)$ & .52 \\
\hline Cerebrovascular disorders & $4(1.7 \%)$ & $0(0.0 \%)$ & $4(7.4 \%)$ & .000 \\
\hline HTN & $54(22.5 \%)$ & $30(16.1 \%)$ & $24(44.4 \%)$ & .000 \\
\hline DM & $92(38.3 \%)$ & $66(35.5 \%)$ & $26(48.1 \%)$ & .09 \\
\hline Other diseases & $32(13.3 \%)$ & $30(16.1 \%)$ & $2(3.7 \%)$ & .01 \\
\hline $\mathrm{O}_{2}$ saturation & & & & .000 \\
\hline Mean \pm SD & $92.43 \pm 8.48$ & $96.01 \pm 3.44$ & $80.07 \pm 9.11$ & \\
\hline$\leq 93$ & $82(34.2 \%)$ & $32(17.2 \%)$ & $50(92.6 \%)$ & \\
\hline$>93$ & $158(65.8 \%)$ & 154 (82.8\%) & $4(7.4 \%)$ & \\
\hline ICU admission & $48(20.0 \%)$ & $8(4.3 \%)$ & $40(74.1 \%)$ & .000 \\
\hline Disease outcome & & & & .000 \\
\hline Improvement & $212(88.3 \%)$ & $186(100 \%)$ & $26(48.1 \%)$ & \\
\hline Death & $28(11.7 \%)$ & $0(0.0 \%)$ & $28(51.9 \%)$ & \\
\hline
\end{tabular}

$P$ values comparing non-severe cases and severe cases are from $X^{2}$ test, Fisher's exact test, or Mann-Whitney $U$ test. A $P$ value of less than 0.05 was regarded as statistically significant 
compare two sample proportions. Spearman's test was used to analyze the correlation between measurement data and ordinal variables while the Pearson correlation was used to evaluate the linear relationship between two continuous variables.

Multivariable binary logistic regression analyses were used to assess the association between age, gender, smoking history, $\mathrm{O}_{2}$ saturation, CT score, $\mathrm{CBC}$, serum ferritin and D-dimer level, and the dependent variable of severity of disease. The odds ratio (OR) along with the 95\% CI were reported. Odds ratio (OR) is a measure of association between exposure and an outcome. The OR represents the odds that an outcome will occur given a particular exposure, compared to the odds of the outcome occurring in the absence of that exposure. A $P$ value of less than .05 was regarded as statistically significant. All statistical analyses were performed using SPSS 20.0 for Windows (SPSS, Inc, Chicago, IL).

\section{Results}

A total of 240 cases diagnosed as COVID-19 infection (188 underwent RT-PCR and 113 cases were positive representing $60.1 \%$ ) were included. The patients were divided into two subgroups severe and non-severe cases whether the case needed ventilatory oxygen support at time of presentation. This was according to the 2019 clinical practice guideline from the Infectious Diseases Society of America and the American Thoracic Society for diagnosis and treatment of adults with communityacquired pneumonia [13].

One hundred eighty-six non-severe cases were recorded; their mean age $\pm \mathrm{SD}=41.88 \pm 14.58$ years, including 96 males (51.6\%) and 90 females (48.4\%). The severe cases counted 54 with mean age \pm SD $=59.37 \pm$ 16.83 years, 44 males (81.5\%) and 10 females (18.5\%). There was significant difference with higher age and large male percentage among the severe group $[p<$
0.0001 and 0.006 respectively]. The severe cases were admitted for 10-21 days, and 28 cases died.

In the analysis of the symptoms that belong to both groups, loss of taste and smell, sore throat, and runny nose were significantly common in non-severe cases $(p<$ 0.0001 for all). On the other hand, dyspnea, chest pain, and expectoration were significantly common among severe cases $(p<0.0001,0.008$, and $<0.0001$ respectively). Regarding the associated co-morbidities, systemic hypertension and cerebrovascular compromise were significantly encountered among severe cases ( $p 0.002$ and 0.008 respectively) (Table 1 ).

The mean oxygen saturation \pm SD was $96.01 \pm 3.44$ for non-severe cases and $80.07 \pm 9.11$ for severe cases $(p$ $<0.0001)$. One hundred fifty-eight cases $(65.8 \%)$ had $>$ $93 \%$, and 82 cases $(34.2 \%)$ had $\leq 93 \%$. The severe cases showed significantly lower levels $(p<0.0001)$.

According to the laboratory results, serum ferritin, Ddimer, and troponin levels were significantly higher in severe patients compared to the non-severe ones ( $p$ $0.002,0.001$, and $<0.0001$ respectively) (Table 2 ).

Regarding CT findings, involvement of both lungs has been reported in 188 cases (78.3\%), 48 cases (20\%) showed unilateral lung affection, and 4 cases (1.7\%) elicited normal lungs. According to lesion location either peripheral involving the outer third or central involving the inner two thirds, 140 cases (58.3\%) showed peripheral lung lesions, 8 cases (3.3\%) with central lesions, and 88 cases $(36.7 \%)$ presented peripheral and central lesions as well.

The commonest pattern encountered on CT was the ground glass opacities (GGOs) representing 96.7\%, followed by consolidations with $39.2 \%$. Air bronchogram was the commonest special CT sign recorded in 92 cases (38.3\%), and the least sign was reverse halo sign in 18 cases (7.5\%) (Table 3).

Regarding the imaging findings, the non-severe cases showed significant frequency of unilateral pulmonary

Table 2 Laboratory findings of the patients

\begin{tabular}{lllll}
\hline & All patients $(\boldsymbol{n}=\mathbf{2 4 0})$ & Non severe cases $(\boldsymbol{n}=\mathbf{1 8 6})$ & Severe cases $(\boldsymbol{n}=\mathbf{5 4})$ & $\boldsymbol{P}$ value \\
\hline Lymphopenia in CBC & $224(93.3 \%)$ & $176(94.6 \%)$ & $48(88.9 \%)$ & $46(85.2 \%)$ \\
High S.ferritin & $144(60 \%)$ & $98(52.7 \%)$ & $44(81.5 \%)$ & .000 \\
High D.dimer & $130(54.2 \%)$ & $86(46.2 \%)$ & $52(96.3 \%)$ & .000 \\
Positive CRP & $238(99.2 \%)$ & $186(100 \%)$ & $4(7.4 \%)$ & .008 \\
Elevated LFT/KFT & $8(3.3 \%)$ & $4(2.2 \%)$ & $16(29.6 \%)$ & .05 \\
High troponin & $22(9.2 \%)$ & $6(3.2 \%)$ & & .000 \\
RT-PCR (done for $\mathbf{1 8 8}$ cases only) & & $(46)$ & $35(76.1 \%)$ \\
& $(188)$ & $(142)$ & $11(23.9 \%)$ \\
Positive & $113(60.1 \%)$ & $78(54.9 \%)$ & $64(45.1 \%)$ & .01 \\
Negative & $75(39.9 \%)$ & &
\end{tabular}

$p$ values comparing non-severe cases and severe cases are from $x^{2}$ test or Fisher's exact test. A $P$ value of less than 0.05 was regarded as statistically significant 
Table 3 CT findings of the patients

\begin{tabular}{|c|c|c|c|c|}
\hline & All patients (240) & Non severe cases $(n=186)$ & Severe cases $(n=54)$ & $P$ value \\
\hline Lesion laterality & & & & 0.001 \\
\hline Unilateral lesions & $48(20 \%)$ & $46(95.8 \%)$ & $2(4.2 \%)$ & \\
\hline Bilateral lesions & $188(78.3 \%)$ & $136(72.3 \%)$ & $52(27.7 \%)$ & \\
\hline Free $C T$ & $4(1.7 \%)$ & $4(100 \%)$ & $0(0 \%)$ & \\
\hline Lesion location & & & & $<0.000$ \\
\hline Peripheral & $140(58.3 \%)$ & $124(88.6 \%)$ & $16(11.4 \%)$ & \\
\hline Central & $8(3.3 \%)$ & $8(100.0 \%)$ & $0(0 \%)$ & \\
\hline Both & $88(36.7 \%)$ & $50(56.8 \%)$ & $38(43.2 \%)$ & \\
\hline Lesion distribution & & & & $<0.000$ \\
\hline Unilobar & $32(13.3 \%)$ & $32(100 \%)$ & $0(0 \%)$ & \\
\hline Bilobar & $104(43.3 \%)$ & $102(98.1 \%)$ & $2(1.9 \%)$ & \\
\hline Multilobar & $100(41.7 \%)$ & $48(48.0 \%)$ & $52(52.0 \%)$ & \\
\hline \multicolumn{5}{|l|}{ Lesion pattern } \\
\hline GGO & $232(96.7 \%)$ & $180(77.6 \%)$ & $52(22.4 \%)$ & $<0.000^{*}$ \\
\hline Consolidation & $94(39.2 \%)$ & $46(48.9 \%)$ & $48(51.1 \%)$ & $0.83^{*}$ \\
\hline Septal lines & $44(18.3 \%)$ & $36(81.8 \%)$ & $8(18.2 \%)$ & $<0.000^{*}$ \\
\hline Crazy paving & $62(25.8 \% 5)$ & $54(87.1 \%)$ & $8(12.9 \%)$ & $<0.000^{*}$ \\
\hline \multicolumn{5}{|l|}{ Special signs } \\
\hline Air bronchogram & $92(38.3 \%)$ & $44(47.8 \%)$ & $48(52.2 \%)$ & $0.67^{*}$ \\
\hline Reverse halo & $18(7.5 \%)$ & $16(88.9 \%)$ & $2(11.1 \%)$ & $0.009^{*}$ \\
\hline Vascular prominence & $28(11.7 \%)$ & $14(50.0 \%)$ & $14(50.0 \%)$ & $1.00^{*}$ \\
\hline White lung & $24(10.0 \%)$ & $0(0 \%)$ & $24(100.0 \%)$ & ------ \\
\hline \multicolumn{5}{|l|}{ Other findings } \\
\hline Lymphadenopathy & $36(15.0 \%)$ & $22(61.1 \%)$ & $14(38.9 \%)$ & $0.19^{*}$ \\
\hline Pleural effusion & $2(0.8 \%)$ & $0(0 \%)$ & $2(100.0 \%)$ & ---------- \\
\hline \multicolumn{5}{|l|}{ CT score } \\
\hline Mean \pm SD & $12.22 \pm 6.02$ & $9.56 \pm 3.42$ & $21.41 \pm 3.34$ & $<0.000^{\#}$ \\
\hline Mild (0-7) & $68(28.3 \%)$ & & & \\
\hline Moderate (8-15) & $118(49.2 \%)$ & & & \\
\hline Severe (16-25) & $54(22.5)$ & & & \\
\hline
\end{tabular}

$P$ values comparing non-severe cases and severe cases are from $x^{2}$ test or Fisher exact test

${ }^{*} P$ values comparing non-severe cases and severe cases are from $Z$ test

${ }^{\#} P$ values comparing non-severe cases and severe cases are from t test. A $p$ value of less than 0.05 was regarded as statistically significant

affection, central location of the lesions, unilobar and bilobar affection, ground glass opacities and septal lines as well as the crazy paving patterns, reverse halo as a special imaging sign, and lower CT severity scores as illustrated in Table 3.

CT-SS ranged from 0 to 25 with mean \pm SD $12.22 \pm$ 6.02. It showed significant negative correlation with $\mathrm{O}_{2}$ saturation and outcome of the patients $(r-0.73 / p 0.001$ and $r-0.56 / p 0.001$ respectively) (Table 4 and Figs. 4 and 5).

Multivariate regression analysis of the most relevant risk factors for severity among patients with COVID-19 revealed that older age, male gender, smoking, hypertension, low $\mathrm{O}_{2}$ saturation, increased CT score, high serum ferritin, and high D-dimer level are the most significant risk factors (Table 5).

Few patients $(9 / 240)$ whom were confirmed by RTPCR had extra-pulmonary manifestations as follows: two cases were diagnosed as myocarditis after normal diagnostic coronary catheterization, three cases had dural venous sinus thrombosis on brain magnetic resonance venography (MRV), two patients with acute lower limb ischemia by Doppler study and CT angiography (a case of complete occlusion of peroneal artery and another 
Table 4 Correlation between CT-severity score and both $\mathrm{O}_{2}$ saturation and disease outcome in patients with COVID-19 infection

\begin{tabular}{lll}
\hline & CT score & \\
\cline { 2 - 3 } & $\boldsymbol{R}$ & $\boldsymbol{P}$ value \\
\hline $\mathbf{O}_{2}$ saturation & -0.79 & .000 \\
Disease outcome & -0.56 & .000 \\
\hline
\end{tabular}

one with anterior tibial artery occlusion), and two patients with acute infarction of middle cerebral artery territory.

\section{Discussion}

By the end of 2019, many cases with a novel febrile chest infection had been reported in Wuhan City, China. Clinical and CT imaging share characteristic findings. Our study has depended primarily on the HRCT to screen cases with clinical and epidemiological data suspicious for COVID-19 infection even with negative or unavailable RT-PCR testing. It has met the recent WHO guidelines [14].

The current study did not depend primarily on RTPCR. This was supported by Bai et al. [15] who stated that CT chest had higher sensitivity in relation to RTPCR, yet the obstacle was to differentiate between COVID-19 pneumonia and other viral pneumonia as well as the organizing pneumonia. Fang et al. [16] has reported $98 \%$ sensitivity for CT chest compared to $71 \%$ for RT-PCR.
Like Wu et al. [17], high fever and dyspnea as a symptom of lower respiratory tract involvement were significantly higher in patients belonged to the severe group compared to the upper respiratory tract symptoms.

On analysis of the imaging features, the bilateral multi-lobar affection with peripheral distribution was the commonest interpreting finding, and GGOs were the most encountered pattern; other reported patterns were consolidations and crazy paving as well as the septal lines. Similar outcome was stated by many studies [6, 18-23].

Thirty-six cases had mediastinal lymphadenopathy (15\%), and 2 cases with pleural effusion (0.8\%) have been reported; this low proportion was in concordance with Bernheim et al. [24]; also, low percentage of cases had septal lines representing (18.3\%) similarly with Pan et al. [10].

In agreement with Zhao et al. [25] who concluded that old age, diffuse pulmonary affection, and more lesions' extent as well as the presence of pleural effusion were significantly frequent among emergency cases compared to the non-emergency cases, there was no significant difference between both groups regarding the gender in their study.

Older age, male sex, smoking, low $\mathrm{O}_{2}$ saturation, increased CT score, and high serum ferritin and high Ddimer level are the most significant risk factors; similar outcome has been reported by $\mathrm{Li}$ et al. [26] and $\mathrm{Wu}$ et al. [17]

Hypertension as co-morbidity was an established risk factor for severity and poor patients' outcome, similarly with Guan et al. [27], Wu et al. [17], Li et al. [26], and

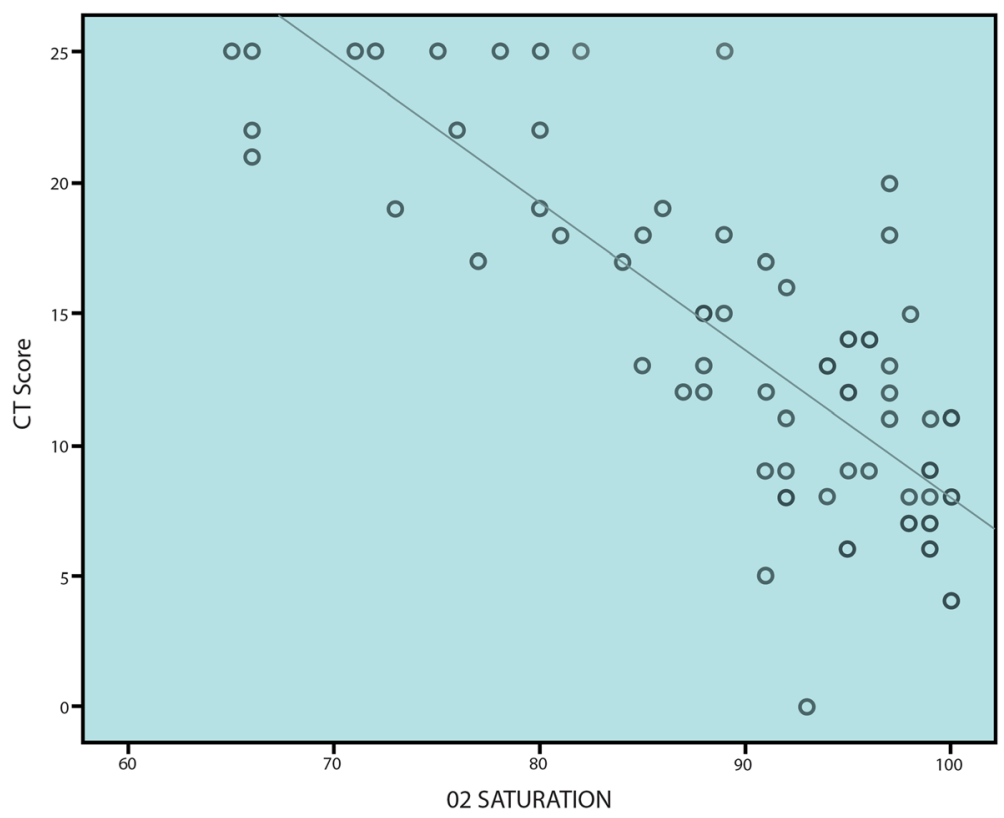

Fig. 4 Scatter correlation graph between $\mathrm{O}_{2}$ saturation and $\mathrm{CT}$-severity score (strong negative correlation) 


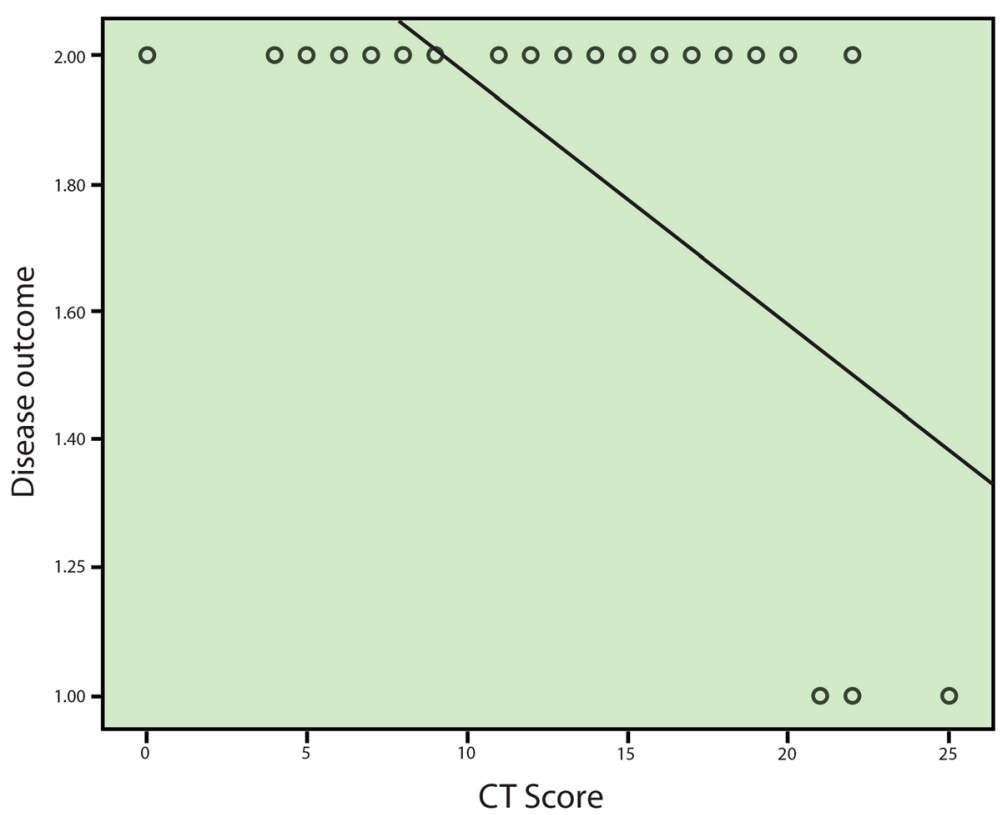

Fig. 5 Scatter correlation graph between CT severity score and patients' outcome (moderate negative correlation)

Table 5 Binary logistic regression analysis for severity among patients with COVID-19 infection

\begin{tabular}{|c|c|c|c|c|c|}
\hline \multirow[t]{2}{*}{ Variables } & \multirow[t]{2}{*}{ Wald } & \multirow{2}{*}{$\begin{array}{l}P \\
\text { value }\end{array}$} & \multirow[t]{2}{*}{ OR } & \multicolumn{2}{|c|}{$95 \% \mathrm{Cl}$} \\
\hline & & & & Lower & Upper \\
\hline \multicolumn{6}{|l|}{ Age } \\
\hline$\geq 65$ years vs $<65$ years & 11.87 & 0.001 & 4.93 & 2.74 & 9.25 \\
\hline \multicolumn{6}{|l|}{ Gender } \\
\hline Male vs female & 6.94 & 0.008 & 2.18 & 1.22 & 3.91 \\
\hline \multicolumn{6}{|l|}{ Smoking history } \\
\hline Smokers vs non-smokers & 7.83 & 0.005 & 3.31 & 1.43 & 7.63 \\
\hline \multicolumn{6}{|l|}{ Hypertension } \\
\hline Yes vs no & 5.18 & 0.02 & 2.13 & 1.45 & 6.72 \\
\hline \multicolumn{6}{|l|}{$\mathrm{O}_{2}$ saturation } \\
\hline$\leq 93$ vs $>93$ & 5.76 & 0.01 & 1.98 & 1.13 & 3.46 \\
\hline CT severity score & 4.40 & 0.03 & 2.75 & 1.06 & 7.11 \\
\hline \multicolumn{6}{|l|}{$\mathrm{CBC}$} \\
\hline Lymphopenia vs normal & 1.46 & 0.22 & 1.59 & 0.74 & 3.39 \\
\hline \multicolumn{6}{|l|}{ S.ferritin } \\
\hline High level vs normal & 6.48 & 0.006 & 2.13 & 1.22 & 4.75 \\
\hline \multicolumn{6}{|l|}{ D.dimer } \\
\hline High level vs normal & 10.36 & 0.001 & 3.88 & 1.69 & 8.85 \\
\hline
\end{tabular}

The Wald test (also called the Wald Chi-squared test) is a way to find out if explanatory variables in a model are significant. "Significant" means that they add something to the model; variables that add nothing can be deleted without affecting the model in any meaningful way
Zhang et al. [28]. As it is known that ACE2 is a vital regulator for cardiac functions, thus it may explain the high frequency of severe COVID-19 pneumonia among the hypertensive patients.

The current study elicited a strong negative correlation between the oxygen saturation and the CT-SS $(r-0.73 / p 0.001)$, and this was different from the weak negative correlation reported by Wang et al. [29] ( $p<0.05$ and $r-0.446)$. There were significant correlations between the degree of pulmonary affection by COVID-19 infection and the main clinical symptoms and laboratory results, and this was in concordance with $\mathrm{Wu}$ et al. [30]. The current study agreed with Zhao et al. [31] who recommended clinical correlation with CT findings.

The globally disseminated COVID-19 infection outbreak is better to be aborted by the recommended protective measures.

\section{Limitation of the study}

The shortage of RT-PCR to include all cases was the main limitation. Other issues included somehow variable duration from the onset of the symptoms and seeking medical advice and investigations. Besides no hospitalbased electronic registry with self-recording of the comorbidities.

\section{Conclusion}

Regarding the current global pandemic of coronavirus infection, HRCT chest is the modality of choice for detecting COVID-19 pneumonia. It tells the clinicians about 
severity using the severity score in interpretation. Older age, male sex, smoking, hypertension, low $\mathrm{O}_{2}$ saturation, increased CT score, high serum ferritin, and high D-dimer level are the most significant risk factors and correlated with poor patients' outcome and mortality.

\section{Recommendations}

We recommend follow-up for the recovered cases to assess probable subsequent pulmonary fibrosis, also to pay attention to extra-pulmonary manifestations of COVID19 infection, and to wait for larger scale studies to increase the awareness and knowledge about the disease and to strengthen the statistical analyses.

\begin{abstract}
Abbreviations
HRCT: High-resolution computed tomography; COVID-19: Coronavirus disease 2019; SARS-CoV-2: Severe acute respiratory syndrome coronavirus 2; ACE 2: Angiotensin-converting enzyme 2; CT: Computed tomography; ICU: Intensive care unit; CT-SS: Computed tomography severity score; $\mathrm{O}_{2}$ : Oxygen; RT-PCR: Real-time transcriptase polymerase chain reaction; MRV: Magnetic resonance venography; GGOs: Ground glass opacities; HTN: Hypertension; CRP: C-reactive protein; CBC: Complete blood count; DM: Diabetes mellitus; LFT: Liver functions tests; KFT: Kidney functions tests
\end{abstract}

\section{Acknowledgements}

Nil.

\section{Authors' contributions}

All authors contributed equally to study design and drafting the manuscript. ER interpreted the $\mathrm{CT}$ imaging for all cases. AH correlated the clinical data and did the medical examination for the cases. GM contributed to data analysis and interpretation of the results. The authors read and approved the final manuscript.

\section{Funding}

Nil.

\section{Availability of data and materials}

Data will be available upon request via contacting the corresponding author.

\section{Ethics approval and consent to participate}

A written consent to participate is available.

Ethics approval: by Menoufia University, Faculty of Medicine, Research Ethics Committee

The reference number is 5/2020RAD4.

\section{Consent for publication}

A written consent for publication is available.

\section{Competing interests}

The authors declare that they have no competing interests.

\section{Author details}

1Department of Radiodiagnosis, Faculty of Medicine, Menoufia University, Shibin el Kom, Menoufia 32511, Egypt. ${ }^{2}$ Department of Chest Diseases and Tuberculosis, Faculty of Medicine, Menoufia University, Shibin el Kom, Egypt. ${ }^{3}$ Department of Public Health and Community Medicine, Faculty of Medicine, Menoufia University, Shibin el Kom, Egypt.

Received: 3 August 2020 Accepted: 27 October 2020

Published online: 25 November 2020

\section{References}

1. (2020) Coronaviruses | NIH (ed) National Institute of Allergy and Infectious Diseases. In: NIH Natl. Institue Allergy Infect. Dis. NIAID https://www.niaid. nih.gov/diseases-conditions/coronaviruses. Accessed 23 Jul 2020
2. CDC (2020) Infection control guidance for healthcare professionals about coronavirus (COVID-19). Centers Dis. Control Prev https://www.cdc.gov/ coronavirus/2019-ncov/hcp/index.html. Accessed 23 Jul 2020

3. World Health Organization (WHO) (2020) World Health Organization. Director-General's remarks at the media briefing on 2019-nCoV on 11 February 2020World Heal Organ, pp 1-6

4. Hoffmann M, Kleine-Weber H, Schroeder S et al (2020) SARS-CoV-2 cell entry depends on ACE2 and TMPRSS2 and is blocked by a clinically proven protease inhibitor. Cell 181:271-280.e8. https://doi.org/10.1016/j.cell.2020.02.052

5. Mcintosh AK (2020) Coronavirus disease 2019 ( COVID-19): epidemiology, virology, and prevention. Lancet Infect Dis https://www.uptodate.com/ contents/coronavirus-disease-2019-covid-19-epidemiology-virology-andprevention. Accessed 23 Jul 2020

6. Chung M, Bernheim A, Mei X et al (2020) CT imaging features of 2019 novel coronavirus (2019-NCoV). Radiology 295:202-207. https://doi.org/10.1148/ radiol.2020200230

7. Yang Q, Liu Q, Xu H et al (2020) Imaging of coronavirus disease 2019: a Chinese expert consensus statement. https://doi.org/10.1016/j.ejrad.2020. 109008

8. Lei J, Li J, Li X, Qi X (2020) CT imaging of the 2019 novel coronavirus (2019NCoV) pneumonia. Radiology 295:18

9. Fang $Y$, Zhang H, Xu Y et al (2020) CT manifestations of two cases of 2019 novel coronavirus (2019-nCoV) pneumonia. Radiology 295:208-209. https:// doi.org/10.1148/radiol.2020200280

10. Pan Y, Guan H, Zhou S et al (2020) Initial CT findings and temporal changes in patients with the novel coronavirus pneumonia (2019-nCoV): a study of 63 patients in Wuhan, China. Eur Radiol 30:3306-3309. https://doi.org/10. 1007/s00330-020-06731-x

11. Reddy S, Ding X, Xu J et al (2020) Chest CT findings of COVID-19 pneumonia by duration of symptoms. Eur J Radiol 127:109009. https://doi. org/10.1016/j.ejrad.2020.109009

12. Sabri YY, Nassef AA, Mohamed I et al (2020) CT chest for COVID-19, a multicenter study - experience with 220 Egyptian patients. Egypt J Radiol Nucl Med 51:144. https://doi.org/10.1186/s43055-020-00263-6

13. Metlay JP, Waterer GW, Long AC et al (2019) Diagnosis and treatment of adults with community-acquired pneumonia. Am J Respir Crit Care Med 200:E45-E67. https://doi.org/10.1164/rccm.201908-1581ST

14. Akl EA, Blazic I, Yaacoub S et al (2020) Use of chest imaging in the diagnosis and management of COVID-19: a WHO rapid advice guide. Radiology 203173. https://doi.org/10.1148/radiol.2020203173

15. Bai HX, Hsieh B, Xiong Z et al (2020) Performance of radiologists in differentiating COVID-19 from viral pneumonia on chest CT. Radiology 200823. https://doi.org/10.1148/radiol.2020200823

16. Fang $Y$, Zhang $H$, Xie J et al (2020) Sensitivity of chest CT for COVID-19: comparison to RT-PCR. Radiology 296:200432. https://doi.org/10.1148/radiol. 2020200432

17. Wu C, Chen X, Cai Y et al (2020) Risk factors associated with acute respiratory distress syndrome and death in patients with coronavirus disease 2019 pneumonia in Wuhan, China. JAMA Intern Med 180:934-943. https://doi.org/10.1001/jamainternmed.2020.0994

18. Omar S, Motawea AM, Yasin R (2020) High-resolution CT features of COVID19 pneumonia in confirmed cases. Egypt J Radiol Nucl Med 51. https://doi. org/10.1186/s43055-020-00236-9

19. Wang $Y$, Dong C, Hu $Y$ et al (2020) Temporal changes of $C T$ findings in 90 patients with COVID-19 pneumonia: a longitudinal study. Radiology 200843. https://doi.org/10.1148/radiol.2020200843

20. Shi $H$, Han $X$, Jiang $N$ et al (2020) Radiological findings from 81 patients with COVID-19 pneumonia in Wuhan, China: a descriptive study. Lancet Infect Dis 20:425-434. https://doi.org/10.1016/S14733099(20)30086-4

21. Salehi S, Abedi A, Balakrishnan S, Gholamrezanezhad A (2020) Coronavirus disease 2019 (COVID-19): a systematic review of imaging findings in 919 patients. AJR Am J Roentgenol 215:87-93. https://doi.org/10.2214/AJR.20.23034

22. Kong WAP (2020) Chest imaging appearance of COVID-19 infection. Radiol Cardiothorac Imaging 2:1. https://doi.org/10.1148/ryct.2020200028

23. Song F, Shi N, Shan F et al (2020) Emerging 2019 novel coronavirus (2019NCoV) pneumonia. Radiology 295:210-217. https://doi.org/10.1148/radiol. 2020200274

24. Bernheim A, Mei X, Huang M et al (2020) Chest CT findings in coronavirus disease 2019 (COVID-19): relationship to duration of infection. Radiology 295:685-691 
25. Zhao W, Zhong Z, Xie X et al (2020) Relation between chest $C T$ findings and clinical conditions of coronavirus disease (covid-19) pneumonia: a multicenter study. Am J Roentgenol 214:1072-1077. https://doi.org/10.2214/ AJR.20.22976

26. Li X, XU S, Yu M et al (2020) Risk factors for severity and mortality in adult COVID-19 inpatients in Wuhan. J Allergy Clin Immunol 146:110-118. https:// doi.org/10.1016/j.jaci.2020.04.006

27. Guan WJ, Liang WH, Zhao Y et al (2020) Comorbidity and its impact on 1,590 patients with Covid-19 in China: a nationwide analysis. Eur Respir J 55. https://doi.org/10.1183/13993003.00547-2020

28. Jin Zl, Dong X, Yuan CY et al (2020) Clinical characteristics of 140 patients infected with SARS-CoV-2 in Wuhan, China. Allergy Eur J Allergy Clin Immunol 75:1730-1741. https://doi.org/10.1111/all.14238

29. Wang K, Kang S, Tian R, Zhang X, YW XZ (2020) Imaging manifestations and diagnostic value of chest CT of coronavirus disease 2019 (COVID-19) in the Xiaogan area. Clin Radiol 75:341-347. https://doi.org/10.1007/s00134-02005991-x.Bizzarro

30. Wu J, Wu X, Zeng W et al (2020) Chest CT findings in patients with coronavirus disease 2019 and its relationship with clinical features. Invest Radiol 55:257-261

31. Zhao W, Xie X, Liu J (2020) Reply to "radiologic findings of coronavirus disease (COVID-19): clinical correlation is recommended". Am J Roentgenol 215:W8

\section{Publisher's Note}

Springer Nature remains neutral with regard to jurisdictional claims in published maps and institutional affiliations.

\section{Submit your manuscript to a SpringerOpen ${ }^{\circ}$ journal and benefit from:}

- Convenient online submission

- Rigorous peer review

- Open access: articles freely available online

High visibility within the field

- Retaining the copyright to your article

Submit your next manuscript at $\boldsymbol{\nabla}$ springeropen.com 